$\overline{\text { Note }}$

\title{
The Effects of Peptidoglycan on the Photocatalytic Bactericidal Activity of Titanium Dioxide
}

\author{
AYANO TAKAO ${ }^{1,2}$, AND TOMONORI SUZUKI ${ }^{1,2 *}$ \\ ${ }^{1}$ Department of Applied Biological Science, Tokyo University of Science, \\ 2641, Yamazaki, Noda, Chiba 278-8510, Japan \\ ${ }^{2}$ Photocatalysis International Research Center, Tokyo University of Science, \\ 2641, Yamazaki, Noda, Chiba 278-8510, Japan
}

Received 15 November, 2019/Accepted 10 March, 2020

\begin{abstract}
For the elucidation of the mechanism underlying the photocatalytic bactericidal activity of titanium dioxide $\left(\mathrm{TiO}_{2}\right)$, we focused on the peptidoglycan layer, a component of the bacterial cell wall. The effect of this layer on the photocatalytic bactericidal activity of $\mathrm{TiO}_{2}$ was evaluated by determining the survival rates of Lactobacillus plantarum (intact cells) and its protoplast cells. Mesoplasma florum, which does not originally possess the peptidoglycan layer, was also used. Our results revealed that the survival rates of the intact cells were lower than those of the protoplast cells. In addition, there was no significance between the survival rates of $M$. florum cells and the protoplast cells of $L$. plantarum. It was suggested that the presence of the peptidoglycan layer increases the bactericidal effect by the photocatalysis.
\end{abstract}

Key words : Photocatalysis / $\mathrm{TiO}_{2}$ / Bactericidal effect / Protoplast / Peptidoglycan.

Various environmental problems such as water and air pollutions are caused by microorganisms and must be addressed. Antibiotics, antibacterial drugs, disinfectants, and other bactericidal agents have been developed as a solution to these issues; however, problems such as the appearance of drug-resistant microorganisms and high drug development costs still persist. For these reasons, a new sterilization technique for overcoming these difficulties is required. As one such promising technique, photocatalysts are attracting attention. Reactive oxygen species (ROS) are generated on the surface of $\mathrm{TiO}_{2}$ following the irradiation of UV light. Such ROS can ultimately decompose organic matter to $\mathrm{CO}_{2}$ and $\mathrm{H}_{2} \mathrm{O}$ (Carré et al., 2014; Fujishima and Honda, 1972; Fujishima et al., 2008; Noguchi et al., 1998; Sopyan et al., 1996). However, there is no clear knowledge regarding the mechanism underlying the bactericidal effect of photocatalysis. While gram-positive bacteria have been reported to be less sterile than gram-negative bacteria owing to the presence of a thick peptidoglycan layer (Kühn et al., 2003; Pal et al., 2007), gram-positive

*Corresponding author. Tel: +81-4-7124-1501, Fax: +81-47123-9767, E-mail : chijun(a)rs.noda.tus.ac.jp bacteria are reportedly more easily sterilized (Tsai et al., 2010). Another study has reported that ROS only passes through the peptidoglycan layer and the reaction occurs only in the outer and inner membranes (Sunada et al., 2003). As mentioned above, the results of photocatalysis in the cell wall are currently contradictory. Therefore, this study aims to assess the influence of peptidoglycan in the cell wall on the photocatalytic activity of $\mathrm{TiO}_{2}$ to clarify the mechanism underlying sterilization.

To evaluate the bactericidal effect by the peptidoglycan layer, we used gram-positive bacteria with a thick peptidoglycan layer. A Gram-positive bacterium generally used in research is Bacillus subtilis. However, $B$. subtilis is a spore-forming bacterium. We thought that the effect of the photocatalysis might be different between spores and vegetative cells. Therefore, we used Lactobacillus plantarum, which does not form spores and has a thick peptidoglycan layer. L. plantarum intact cells with a very thick peptidoglycan layer and $L$. plantarum protoplast cells without a peptidoglycan layer were used to confirm whether the bactericidal effect differs depending on the presence or absence of peptidoglycan layer as the main component of the cell wall. Since $L$. 
plantarum is a rod-shaped bacterium, it can be readily distinguished from protoplast cells rounded by removing the cell wall.

L. plantarum JCM1149 ${ }^{\top}$ was used for the bactericidal experiments. This strain was obtained from the Japan Collection of Microorganisms. L. plantarum JCM1149 cells were statically cultured in de Man, Rogosa, and Sharpe (MRS) broth (Difco) at $30{ }^{\circ} \mathrm{C}$ for $3.5 \mathrm{~h}$ until early log phase. The cells were washed twice with $0.2 \mathrm{M}$ phosphate-buffer ( $\mathrm{pH}$ 6.8) and once with MASH buffer (pH 6.5) contained (per litter): $4.8 \mathrm{~g}$ of HEPES, $6.0 \mathrm{~g}$ of $\mathrm{MgCl}_{2} \cdot 6 \mathrm{H}_{2} \mathrm{O}, 684.6 \mathrm{~g}$ of sucrose and $5.0 \mathrm{~g}$ of gelatin. The composition of MASH buffer was determined by consideration of conditions to be optimal in maintaining the form of protoplast cells. The cells were re-suspended in MASH buffer to OD (Optical Density) at $660 \mathrm{~nm}$ of 0.5. This solution was used as the bacterial suspension of intact cells. The bacterial suspension of protoplast cells was prepared as follows. First, Lysozyme (from Egg White, Wako Pure Chemical Industries, Ltd.) and Labiase (Cosmo Bio Co., Ltd.) were mixed in MASH buffer at $15 \mathrm{mg} / \mathrm{mL}$ each to prepare the enzyme solution. This enzyme solution $(180 \mu \mathrm{L})$ was added to the intact cells suspension $(1 \mathrm{~mL})$ and treated at $37^{\circ} \mathrm{C}$ for $30 \mathrm{~min}$. This solution was used as the bacterial suspension of protoplast cells.

We investigated the bactericidal effect of photocatalyst using $\mathrm{TiO}_{2}$ coated glass, which does not need into consideration in nanoparticle toxicity. The preparation of $\mathrm{TiO}_{2}$ coated glass was performed as follows. Borosilicate glass (TEMPAX: $50 \times 50 \times 2$ mm, Hiraoka Special Glass Mfg. co., Ltd.) was washed with acetone, ethanol and water, and ozone treated by UV Ozone Cleaner UV253E (Filgen, Inc.) for 30 min. The ozonized glass was spin-coated $(1,500 \mathrm{rpm}, 10 \mathrm{~s})$ with $1 \mathrm{~mL}$ of NDH-510C $\left(\mathrm{TiO}_{2}\right.$, Nippon Soda Co., Ltd.) by Spin coater (MS-A200, Mikasa Co., Ltd.). This $\mathrm{TiO}_{2}$ coated glass was baked at $500{ }^{\circ} \mathrm{C}$ for $2 \mathrm{~h}$ in a muffle furnace (KDF-S70, Sansyo Co., Ltd.).

The photocatalytic effect on bacteria was evaluated to assemble the equipment based on Japanese Industrial Standards (JIS R-1702). All the constituent parts of the equipment were washed with $70 \%$ ethanol and irradiated with UVC overnight. The $\mathrm{TiO}_{2}$ coating glass was placed on a plastic stage on a sheet of filter paper moistened in sterile water placed in a petri dish. $0.3 \mu \mathrm{L}$ of LIVE/DEAD ${ }^{\circledR}$ BacLight $^{\text {TM }}$ Bacterial Viability Kit solution (Molecular Probes) was added each to $100 \mu \mathrm{L}$ of the bacterial suspension of intact cells and protoplast cells. Each $10 \mu \mathrm{L}$ of the sample was dropped on the different $\mathrm{TiO}_{2}$ coating glass. $22 \times 22 \mathrm{~mm}$ cover glass was placed thereon, and the petri dish was covered with a wrap. The irradiation intensity of UVA (FL15BL-B, Panasonic) was adjusted to $0.25 \mathrm{~mW} / \mathrm{cm}^{2}$ (Fig. 1). This irradiation intensity is equivalent to the intensity of sunlight that is inserted into the window. Since LIVE/DEAD ${ }^{\circledR}$ BacLight $^{\mathrm{TM}}$ Bacterial Viability Kit is discolored by UVA irradiation, the photocatalysis was performed for up to $2 \mathrm{~h}$. After the photocatalysis, the survival rate was calculated from the numbers of green fluorescent cells as live cells and red fluorescent cells as dead cells using a confocal laser microscope (LSM EXCITER-ZEN 2008, ZEISS). The conventional survival rate evaluation is based on the colony count method. In this method, the operation of spreading the bacterial solution on an agar plate is required. However, L. plantarum protoplast cells are weak to physical stress due to their lack of cell walls. Therefore, the survival rate evaluation by LIVE/DEAD ${ }^{\circledR}$ BacLight ${ }^{\mathrm{TM}}$ Bacterial Viability Kit, which is a viability test based on the degree of membrane damage, was conducted instead of the colony count method.

A photocatalysis was performed on the protoplast cells and the intact cells of $L$. plantarum. The survival rate of the protoplast cells decreased to $86 \%$ for $1 \mathrm{~h}$ of photocatalytic treatment and to $85 \%$ for $2 \mathrm{~h}$. The survival rate of the intact cells decreased to $64 \%$ for $1 \mathrm{~h}$ of photocatalytic treatment and to $50 \%$ for $2 \mathrm{~h}$. Statistical analysis (Student's t-test) revealed that the time course of survival rates by photocatalytic treatment was significantly different between the protoplast cells and the intact cells (Fig. 2). The result that the survival rate of the intact cells was significantly lower than that of the protoplast cells led to the idea that the reduction of the survival rate was suppressed by the protein added to prepare the protoplast cells.

In order to ascertain the influence of cell wall digesting enzyme added at preparing protoplast cells, the survival rate was evaluated by adding albumin without Lysozyme and Labiase activity. After the addition of albumin to the suspension of the intact cells, the photocatalytic treatment was performed in the experimental equipment (Fig.1). The final concentration of the albumin was the same as the optimum cell wall digesting enzyme concentration for the preparation condition of the protoplast cells. The survival rate of the intact cells without albumin decreased to $91 \%$ for $1 \mathrm{~h}$ of the photocatalytic treatment and to $75 \%$ for $2 \mathrm{~h}$. The survival rate of the intact cells with albumin decreased to $98 \%$ for $1 \mathrm{~h}$ of photocatalytic treatment and to $79 \%$ for $2 \mathrm{~h}$. According to the results of statistical analysis, there were no significant differences in the effects of the photocatalytic reaction of the intact cells with or without protein (Fig 3). Therefore, the possibility that the decrease in the survival rate was suppressed by the presence or absence of the addition of the protein was denied. Also, the survival rate of the protoplast cells was $99 \%$ even for $2 \mathrm{~h}$ of photocatalytic treatment. According to the results of statistical analysis, there was a significant difference 
(A)

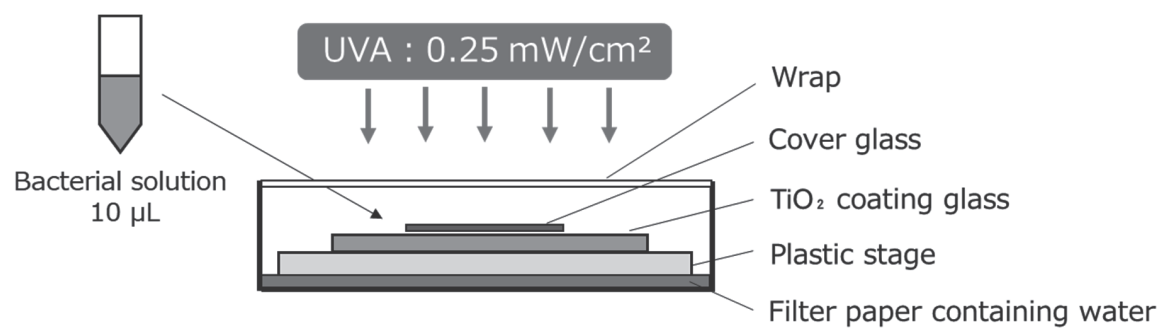

(B)

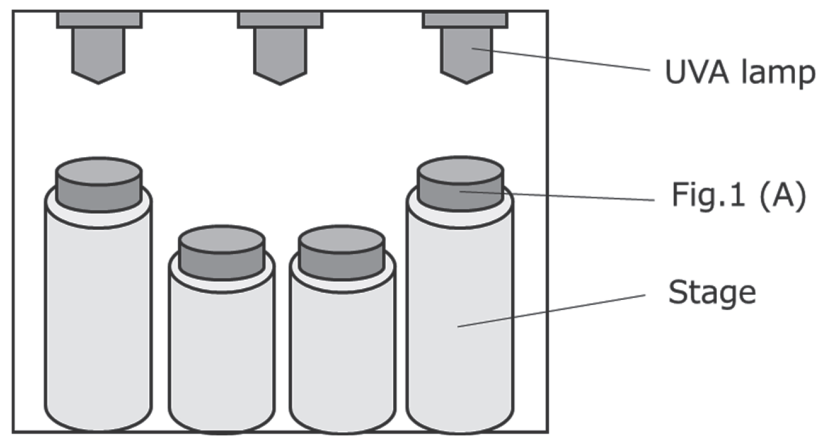

FIG. 1. The experimental equipment using in photocatalytic treatment.

(A) The experimental equipment was based on JIS R-1702. Photocatalytic treatment was carried out in this experimental equipment. A sheet of filter paper containing $4 \mathrm{~mL}$ of sterilized water was laid on the bottom so that the bacterial solution was not dried by UVA irradiation heat.

(B) Inside the UVA irradiation device for photocatalytic treatment. Three UVA lamps are installed at the top inside the device. The plastic Petri dishes were stacked to make a stage so that the UVA intensity of each top of the stage was $0.25 \mathrm{~mW} / \mathrm{cm}^{2}$. "(A)" was placed on the stage, and the photocatalytic treatment was performed.

in the photocatalytic reaction effects between the protoplast cells and the intact cells added protein (Fig 3). In other words, the difference in the survival rate between the protoplast cells and the intact cells for $2 \mathrm{~h}$ of the photocatalyst treatment in Fig. 3 is considered to be due to the presence or absence of the peptidoglycan layer.

L. plantarum protoplast cells are the cells from which the peptidoglycan layer has been removed by enzymatic treatment. That is, it is difficult to assert that the protoplast cells have completely lost the peptidoglycan layer. Therefore, in order to strictly evaluate the effect of the peptidoglycan layer, we also used Mesoplasma florum NBRC100688 ${ }^{\top}$ which originally have no cell wall. This strain was obtained from the National Institute of Technology and Evaluation. M. florum cells were cultured in ATCC 1161 medium at $30^{\circ} \mathrm{C}$ with shaking for $18 \mathrm{~h}$ until early log phase. The cells were washed with SerumSucrose-HEPES (RUSH) buffer ( $\mathrm{pH}$ 6.5) contained (per litter): $0.6 \mathrm{~g}$ of HEPES, $22.6 \mathrm{~g}$ of $\mathrm{NaCl}, 0.39 \mathrm{~g}$ of 2-Mercaptoethanol, $0.25 \mathrm{~g}$ of sucrose and $250 \mathrm{~mL}$ of
Horse serum. The cells were re-suspended in RASH buffer to OD (Optical Density) $660 \mathrm{~nm}$ of 0.5. This solution was used as the bacterial suspension of $M$. florum cells. The survival rate of $M$. florum cells decreased to $98 \%$ for $2 \mathrm{~h}$ of the photocatalytic treatment. Also, the survival rate of $L$. plantarum protoplast cells decreased to $99 \%$ for $2 \mathrm{~h}$ of the photocatalytic treatment. Statistical analysis showed that there was no significant difference between the photocatalytic bactericidal susceptibilities of $M$. florum cells and the protoplast cells of $L$. plantarum (Fig 4). Therefore, it showed that the survival rate of the cells without the peptidoglycan layer did not decrease in the photocatalysis for $2 \mathrm{~h}$.

To summarize above, it was revealed that the survival rate of the cells possessing the peptidoglycan layer tends to decrease, and the survival rate of the cells without the peptidoglycan layer is unlikely to decrease. That is, it is strongly suggested that the peptidoglycan layer might enhance the bactericidal effect by photocatalysis. 


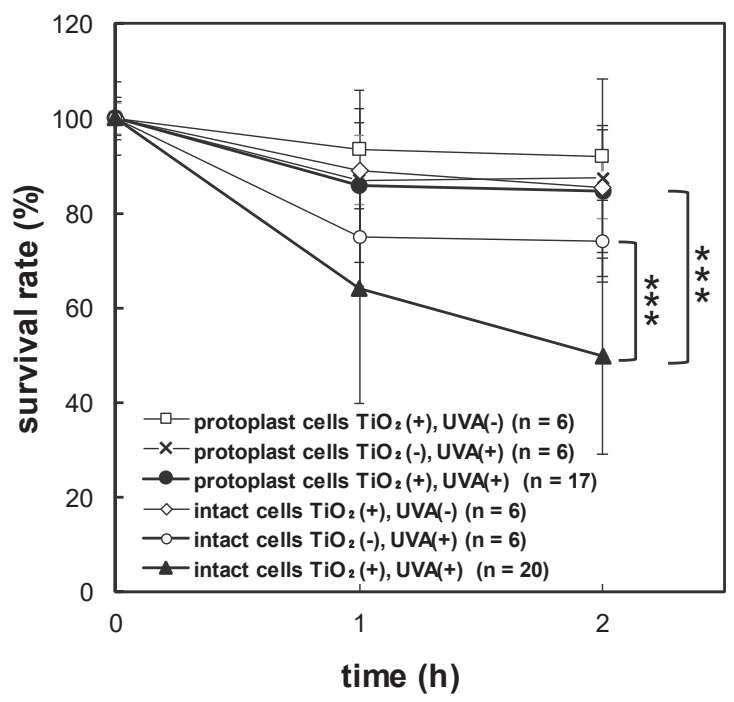

FIG. 2. The survival rates of the protoplast cells and the intact cells by the photocatalytic treatment.

The survival rate of the protoplast cells was about $86 \%$ for $1 \mathrm{~h}$, about $85 \%$ for $2 \mathrm{~h}$ of the photocatalytic treatment. There was no significant difference from the survival rate of the negative controls. The survival rate of the intact cells was about $64 \%$ for $1 \mathrm{~h}$, about $50 \%$ for $2 \mathrm{~h}$ of the photocatalytic treatment. There was significant differences from the survival rate of the negative controls $\left(\left[\mathrm{TiO}_{2}(+)\right.\right.$, UVA (-)]: $\mathrm{p}<0.05,\left[\mathrm{TiO}_{2}(-)\right.$, UVA (+)]: p $<0.001)$. Comparing the survival rate of the protoplast cells and the intact cells by the photocatalytic treatment, there was a significant difference in the viability of both cells $(p<0.001)$. " $n$ " indicates the number of times of the photocatalytic treatment experiment was performed.

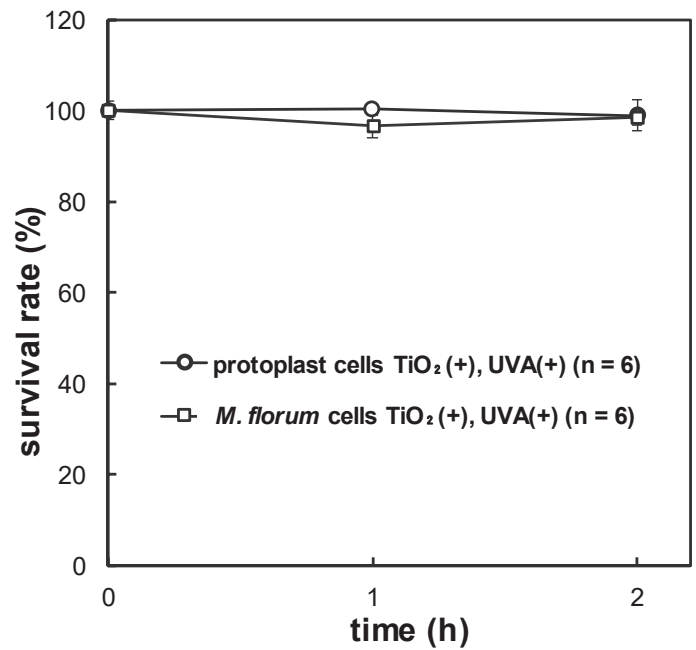

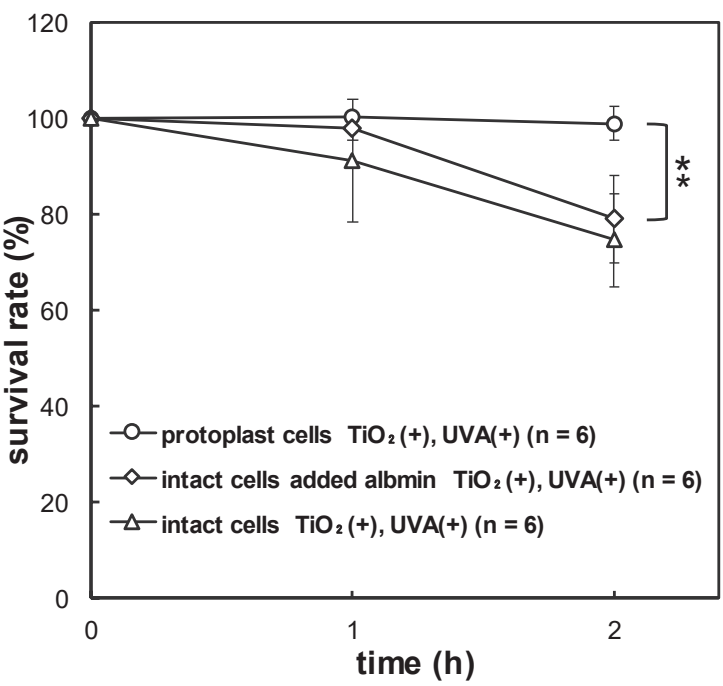

FIG. 3. The survival rate of the intact cells with added albumin by the photocatalytic treatment.

The survival rate of the intact cells without albumin addition was about $91 \%$ for $1 \mathrm{~h}$, about $75 \%$ for $2 \mathrm{~h}$. On the other hand, the survival rate of the intact cells with albumin addition was about $98 \%$ for $1 \mathrm{~h}$, about $79 \%$ for $2 \mathrm{~h}$. There were no significant differences between these conditions $(p<0.05)$. The survival rate of the protoplast cells was about $99 \%$ even for 2 $\mathrm{h}$. The significant difference was observed between the intact cells with albumin addition and the protoplast cells $(p<0.01)$. " $n$ " indicates the number of times of the photocatalytic treatment experiment was performed.
FIG. 4. The comparison between the survival rates of $M$. florum cells and the protoplast cells by the photocatalytic treatment.

The survival rate of $M$. florum cells originally without cell wall was about $98 \%$ even for $2 \mathrm{~h}$. There was no significant difference between the survival rates of $M$. florum cells and the protoplast cells $(p<$ $0.05)$. " $n$ " indicates the number of times of the photocatalytic treatment experiment was performed. 


\section{REFERENCES}

Carré, G., Hamon, E., Ennahar, S., Estner, M., Lett, M., Horvatovich, P., Gies, J., Keller, V., Keller, N., and Andrea, P. (2014) $\mathrm{TiO}_{2}$ Photocatalysis Damages Lipids and Proteins in Escherichia coli. Applied and Environmental Microbiology, 80, 2573-2581.

Fujishima, A., and Honda, K. (1972) Electrochemical photolysis of water at a semiconductor electrode. Nature, 238, 37-38.

Fujishima, A., Zhang, X., and Tryk, D.A. (2008) $\mathrm{TiO}_{2}$ photocatalysis and related surface phenomena. Surface Science Reports, 63(12), 515-582.

Kühn, K.P., Chaberny, I.F., Massholder, K., Stickler, M., Benz, V.W., Sonntag, H.G., and Erdinger, L. (2003) Disinfection of surfaces by photocatalytic oxidation with titanium dioxide and UVA light. Chemosphere, 53(1), 71-77.

Noguchi, T., Fujishima, A., Sawunyama, P., and Hashimoto, K. (1998) Photocatalytic Degradation of Gaseous Formaldehyde Using $\mathrm{TiO}_{2}$ Film. Environmental Science \& Technology, 32, 3831-3833.
Pal, A., Pehkonen, S.O., Yu, L.E., and Ray, M.B. (2007) Photocatalytic inactivation of Gram-positive and Gramnegative bacteria using fluorescent light. Journal of Photochemistry and Photobiology A: Chemistry, 186(2-3), 335-341.

Sopyan, I., Watanabe, M., Murasawa, S., Hashimoto, K., and Fujishima, A. (1996) An efficient $\mathrm{TiO}_{2}$ thin film photocatalyst: Photocatalytic properties in gas-phase acetaldehyde degradation. Photochemistry and Photobiology, 98(1-2), 79-86.

Sunada, K., Watanabe, T., and Hashimoto, K. (2003) Studies on photokilling of bacteria on $\mathrm{TiO} 2$ thin film. Journal of Photochemistry and Photobiology A: Chemistry, 156, 227-233.

Tsai, T.M., Chang, H.H., Chang, K.C., Liu, Y.L., and Tseng, C.C. (2010) A comparative study of the bactericidal effect of photocatalytic oxidation by $\mathrm{TiO}_{2}$ on antibiotic-resistant and antibiotic-sensitive bacteria. Journal of Chemical Technology and Biotechnology, 85(12), 1642-1653. 